\title{
The 2005 SRTR Report on the State of Transplantation
}

Organ donation and transplantation continues to be a fastchanging field, marked by new strides in clinical care and advances in our understanding of many facets of this complex endeavor. As in previous years, the Scientific Registry of Transplant Recipients (SRTR) has again gathered pre-eminent authorities in transplantation to review the latest data submitted to the Organ Procurement and Transplantation Network (OPTN). The data underlying the important papers in this issue can be found in the tables of the OPTN/SRTR Annual Report, published each year by the Health Resources and Services Administration (HRSA) of the U.S. Department of Health and Human Services. Additional analyses have been also been performed to shed light on important new areas, as part of our ongoing effort to identify emerging data trends in the field of transplantation. The issue you are now reading is the fourth annual SRTR Report on the State of Transplantation and represents the product of those efforts.

This year, we brought together 59 nationally and internationally recognized experts to critically review and explain trends in solid organ transplantation in the United States over the past 10 years. In this edition of the report, we commissioned two special focus articles. The first provides an explication of the development of the new lung allocation policy, based largely on transplant survival benefit and implemented in May 2005. The second article explains the details and methodologies used for center-specific reports that are provided to the public every six months for every transplant program in the United States. The SRTR team will continue to offer cutting-edge special focus articles like these each year.

The SRTR Report on the State of Transplantation is a yearlong effort that brings together a very dedicated group of people. As the guest editor, I am very pleased to work with all of them. Dr. Philip Halloran, Editor-in-Chief of the American Journal of Transplantation, has been our stalwart ally and continues to challenge to us to improve the report each year. Pamela Publicover and Treena Fenniak at the AJT editorial office have kept us on track through another yearlong gestation. As usual, their meticulous oversight of manuscript submission and assignment to reviewers kept the peer-review process moving smoothly. We are also pleased that our excellent relationships with Blackwell, especially Eric Rozario, Alison Labbate, and Cynthia Korisky, have continued to facilitate the production and distribution of the report.

Our colleagues at the Division of Transplantation at HRSA were extremely helpful. In particular, we are grateful to James Burdick, Michael Dreis, Gregory Fant, Henry Krakauer, Monica Lin, Virginia McBride, Jade Perdue, Laura St. Martin and Hui-Hsing Wong for their participation, advice and encouragement.

Our 59 authors, representing specialists in every area of clinical transplantation, fulfilled their writing tasks admirably and were responsive to a very tight timetable. I am indebted to each and every author for making the SRTR Report on the State of Transplantation a priority over the course of the year. The lead authors this year were particularly outstanding and organized.

This project simply could not be accomplished successfully without the support, encouragement, and extraordinarily hard work of my colleagues at the University Renal Research and Education Association (URREA) and the University of Michigan. I would like to publicly recognize the principals of the SRTR project, Drs. Friedrich K. Port (Principal Investigator), Robert A. Wolfe, Alan B. Leichtman, Akinlolu O. Ojo, Susan Murray, Douglas E. Schaubel, Jack D. Kalbfleisch, John C. Magee, and Randall S. Sung. Many of the SRTR's analysts, programmers, and administrative staff from the University of Michigan and URREA contributed to this report, including Valarie B. Ashby, Rami T. Bustami, John O. Chen, Kerry Colligan, Laura L. Christensen, Charlene R. Cole, David M. Dickinson, Nathan P. Goodrich, Mary K. Guidinger, Tempie H. Shearon, Gregory N. Levine, Keith P. McCullough, Joshua J. McGowan, Sarah K. Naperala, Trinh B. Pifer, Nicole M. Robidoux, Ann M. Rodgers, Camelia Sima, Randall L. Webb, and James C. Welch.

A few people especially stand out. Sarah N. Miller was the administrative project lead for the SRTR team. Her hard work, good judgment, energy and humor were welcome. 


\section{Preface}

With her usual cheer, Shiqian Li responded to requests for special analyses and prepared the hundreds of reference tables that form the basis for these articles, supplying drafts to authors and incorporating their feedback. Miles P. Finley, with Sandra J. Crump, Jennifer L. McCreadyMaynes and Caroline A. Shevrin, managed the drafts and revisions of the articles from the editorial perspective, coordinated the peer-review process among coauthors, expertly edited text and graphics, and ensured that a uniform stylistic approach was applied to each manuscript. Their skills and attention to detail are top-notch.
The contents of this issue reflect the hard work and insight of many people, and credit for success of the project goes to every person who participated. We believe that this year's report is the best and most useful yet published. Once you have had a chance to peruse the issue, we hope that you will agree.

Robert M. Merion, M.D.

Director, Clinical Transplantation, SRTR

Professor of Surgery

University of Michigan 